\title{
El mundo de la modestia y las buenas maneras
}

Escobar Ceballos, Cecilia, (2005), Manual Orihuela. Consejos a MIS HIJAS. MANUAL ESCRITO POR UN PADRE DE FAMILIA EN VÍSPERAS DEL nuevo siglo, Miguel Ángel Porrúa, MéXico, 181 PP., ISBN: 970701-571-3

Esta (¿̇qué se yo como pudo ser?) dizque supo mucho aunque era mujer. Porque como dizque dice no sé quién, ellas sólo saben, hilar y coser.

Poema de Sor Juana Inés de la Cruz.

Los cambios bruscos en el nivel de vida de una sociedad traen consigo el intento de imponer nuevos cánones de urbanidad y de comportamiento, difundidos en cartillas, catecismos y manuales. Conocidos en Occidente desde el siglo xvi, proliferaron en el siglo XIX. En México, las clases altas, al incrementar su riqueza e intensificar el comercio con otros países europeos hacia mediados del siglo XIX, se preocuparon por mejorar sus modales. Había bastante que aprender, pues con los nuevos consumos variaron utensilios de mesa y cocina, modas, atuendo, muebles, elementos decorativos y hasta el sentido del gusto, alterándose modales y hábitos de vida. Se tradujeron varios manuales de urbanidad de Francia, referencia obligada del mundo "civizado" en tales asuntos, y algunos autores.

El libro del holandés Erasmo de Rotterdam titulado De civilitae morum puerilium libellus (De la urbanidad en las maneras de los niños), es un antecedente de los manuales de buenas maneras que luego proliferaron en España. Este texto fue publicado por vez primera en Basilea en 1530. Se considera que introdujo plenamente en la civilización occidental el nuevo concepto de civilidad social y fase de desarrollo social frente a la barbarie y a la ignorancia; asimismo inauguró un nuevo concepto de civilitas: la "civilidad" ya no representa el ordenamiento y el gobierno de la ciudad ni los hábitos o costumbres de una comunidad. Ciertamente, el tratado de Erasmo se emparenta con los antiguos tratados de cortesía (politesse) y los tratados destinados a las artes de amar o agradar; sin embargo, a diferencia de éstos no se diri- 
ge ya a un sector social determinado, sino a todo hombre que quiera ser educado para la vida social.

En los países americanos, sin duda el célebre Manual de urbanidad y buenas maneras, del venezolano Manuel Antonio Carreño, fue el de mayor influencia y éxito, debido a que en él se recogen las formas más elementales y la reglas sobre los buenos modales para relacionarse en sociedad. Incluso, en la introducción de este manual se asegura que la urbanidad es manifestación de virtud; reflejo exterior de realidades interiores, la intención de integrarse positivamente en la vida ciudadana convertida en hechos.

Desde su publicación en 1853, el Manual de Carreño se convirtió rápidamente en lectura obligada para la gente de su época. De este Manual encontramos en México una gran cantidad de ediciones, especialmente durante el último tercio del siglo XIX. Otros textos similares, en la forma y en el contenido, fueron editados y reeditados en nuestro país; algunos dedicados exclusivamente a los niños y otros destinados a todo ser humano que desease ser aceptado y aprobado en las esferas más altas de la sociedad de aquella época. Muchos de estos textos, como el propio Manual de Carreño, fueron adaptados para su utilización en establecimientos educacionales. Cabe señalar que aquellos peculiares tratados de urbanidad siempre habían existido para las clases pudientes y las familias "honorables" de la época.

Estos libros abarcaban el comportamiento en todas las esferas de la vida en la familia, en la escuela, en la calle, en la iglesia y en todos los ámbitos sociales, y también indicaban cuál era la actitud, la palabra, el comportamiento socialmente correctos. "Los niños bien educados jamás deben salir a la calle a formar juegos y retozos que necesariamente han de molestar a los vecinos" (Carreño, 1853: 34), se leía en el compendio del Manual de urbanidad y buenas maneras. Los consejos, en muchas ocasiones se repartían entre los niños y las niñas. Por ejemplo, la "Cartilla moderna de urbanidad" para niñas decía que a la niña bien educada "le gusta entretener a sus hermanitos y suele jugar a lo que otros prefieren, en los juegos de prendas es discreta para no molestar ni darse por ofendida" (Carreño, 1853: 37), entre otras pautas. Mientras los niños debían, según otro texto, ser cariñosos y buenos compañeros cediendo al gusto de los otros siempre que pudieran, hacer favores siempre que pudieran, aunque fuera a forasteros o desconocidos, ello en unas páginas que se ilustraban además a modo de cómic. 
En ese contexto histórico apareció la obra de don Manuel Orihuela titulada Consejos a mis hijas, escrita en 1874, obra que Cecilia Escobar Ceballos nos da a conocer en su libro: Mawad Orihuela. Consejos a mis hijas. Manual escrito por un padre de familia en vísperas del nuevo siglo. Este trabajo se inscribe en el marco de la literatura moral de "Tratados de buenas maneras" o "Tratados de urbanidad”. En estos escritos se establecieron, sin más, nociones éticas de comportamiento, y constituían un conjunto de preceptos para la vida social y el buen trato entre los hombres. En la expresión "tratados de urbanidad" late, sin duda, la oposición entre las exigencias de la vida de ciudad y las de la vida campesina. De allí que la expresión "urbano" se emplee como equivalente de educado, cortés, civil, fino, correcto, y se oponga a rústico o grosero. Al mismo tiempo, es claro que en estos manuales, no obstante su carácter no estrictamente moral, existe una ostensible tesitura moral: decir de una persona que es cortés o urbana equivale tanto como a decir que es comedida o mesurada.

El libro de Cecilia Escobar Ceballos, que ahora reseñamos, contiene dos obras en un solo trabajo, y ambas son muy ricas. Por una parte, el estudio que la autora realiza del manuscrito, y, por la otra, el documento paleografiado de don Manuel Orihuela. La primera está constituida por cinco capítulos y una bibliografía. La segunda está integrada con los consejos del licenciado Orihuela, y se titula versión paleográfica realizada por Cecilia Escobar Ceballos.

En el preámbulo de la primera parte se nos habla de la historia de una familia en la ciudad de México, lo cual debe alabarse o criticarse en razón de que la autora se basa en un libro de su propia familia. La estrategia es difícil, porque debe prevalecer su objetividad como historiadora, y lo logra. Ella misma asegura que el propósito de su publicación es que el documento sea utilizado en investigaciones futuras sobre la vida cotidiana de la clase media en el México decimonónico. También nos explica que, en su primera versión, el manuscrito fue presentado en el seminario de la licenciatura para el Departamento de Historia de la Universidad Iberoamericana. Su éxito fue tan grande que llevó a la licenciada Escobar Ceballos a buscar más información en los periódicos de la época con objeto de enriquecer el material con el que contaba.

El manual de don Manuel Orihuela, quien fuera juez y escribano público de la ciudad de México a finales del siglo XIX, tuvo un claro objetivo: escribir consejos para sus hijas con el fin de 
cuidar de ellas y preservar el honor de su familia. Incluso, el licenciado Orihuela ratificó su interés en que sus hijas continuaran las prácticas comunes de mujeres de bien de los estratos medios de la población finisecular mexicana, aspecto muy común en la época cuando la familia se había quedado sin madre.

Recordemos que la sociedad en el México decimonónico intentaba "igualar" a todos sus habitantes. El problema era complejo y difícil, aunque las sociedades cambiaban lentamente y en todo ese siglo se intentó una transición entre la colonia y la sociedad "republicana". Durante esa época, la pirámide social estaba integrada por tres sectores: la clase oficialistas, formada por el ejército y la burocracia, ambos ineficientes e irregulares; la clase media y la popular, integrada por rancheros, indios, peones, trabajadores de las minas, obreros, sirvientes, vendedores ambulantes, dulceros, voceadores de periódico, eloteros, lecheros, pepenadores, aguadores y, por supuesto, los llamados "léperos".

Los consejos de don Manuel Orihuela están dedicados a su hija mayor, Lugarda Orihuela, quien sustituía a la madre muerta y asumía las labores hogareñas y maternales y el cuidado de los hermanos más jóvenes. Su interés era transmitir valores cívicos, como honradez, lealtad, educación y ahorro, así como cuestiones morales: amistad, envidia, e interrelación entre hombre y mujer, siguiendo las normas que la sociedad establecía. Es una historia de vida cotidiana y de la buena sociedad de la época.

En el capítulo primero, titulado "Rescatando la moral", se dan los pormenores de la clase social a la que pertenecía la familia Orihuela: “clase media mexicana”, cuyas prácticas y comportamientos característicos eran del ambiente urbano. En este manual se hace el rescate de los valores decentes de la clase media, portadora de la moral y la buena educación; los cuales servían para aplicarse a las actividades diarias.

Las mujeres trabajaban dentro del hogar realizando las labores domésticas, como planchar, cocina, barrer y cuidar de los hijos; además se les inculcaba el ahorro, la sobriedad, la higiene y el trabajo, que propiciarían el progreso del país. Su objetivo era lograr una sociedad de gente "civilizada". Ejemplo de ello es que en el manual, al hablarse de los conceptos de limpieza y de ahorro, se asegura que la clase baja no era limpia porque no tenía los recursos para serlo; los indios eran sucios por "miseria y no por tradición". Por su parte, la clase alta, al tener varios sirvientes que hacían la limpieza del hogar, no se preocupaban por ésta, volviéndose indiferentes ante el aseo; como diría don Ma- 
nuel, "las ricas son puercas". La limpieza era la pureza, y esto se deja claro en el documento. Esta idea de diferenciar y de diferenciarse como grupo, no solamente se tenía en México, sino también en Europa y en los Estados Unidos.

Otro consejo era que las mujeres jóvenes debían ser laboriosas, y para ello se les instruía en costura, cocina, lavandería, barrida, pintura, música y canto. Además de esta instrucción, conocida como labores femeninas, se les inculcaba la humildad, el ahorro, el recato, el buen gusto y la modestia, que era el atributo más hermoso del sexo femenino.

Cabe resaltar la idea del ahorro, que constituía la muestra del equilibrio que se buscaba tener en la vida, asegurando este padre de familia que el dinero no debía faltar, pero tampoco se debía ser ostentoso con él, y ello evidenciaba que si se sabía ahorrar, era porque se sabía ganar, por medio del trabajo. El valor real de todos estos valores dependía de la importancia que se les había dado a los mismos en la educación. Incluso, don Manuel Orihuela aseguraba que una "buena educación, si no se aprende en los primeros años de la vida es imposible que en la edad madura pueda aprenderse; esto es un evangelio". Así que educar e instruir y aconsejar era la tarea principal de los padres y tutores, que por su experiencia eran capaces de formar el carácter de una persona. Ellos eran quienes abrirían las puertas del mundo, sobre todo cuando los padres o tutores llegaban a la tercera época del hombre, la de hablar consigo mismos.

La mujer decimonónica debía ser laboriosa y hacer el trabajo con sus propias manos, ser honrada, respetuosa, saber de economía y de administración del dinero, sobre todo si se quería hacer de ella una persona "decente", entendiéndose por persona "decente”, en esa época, una que mereciera la confianza pública por su ciencia, su prudencia y su moralidad.

En suma, la mujer era la portadora de los principios morales y también de las enseñanzas religiosas, sabiéndose comportar ante la sociedad sin importar el evento o la compañía. Ser una persona educada también significaba ser una persona civilizada, cultivada. "Se tenía que conocer el comportamiento en las comidas, como el manejo de los cubiertos, las conversaciones atinadas para el momento, las reglas de etiqueta en un baile o en un teatro, la manera de saludar a las mujeres u hombres en lugares públicos y privados, así como la forma de vestir para cada ocasión" (Escobar, 2005: 58-59). 
En el capítulo segundo titulado "¿Quién es Manuel Orihuela?", Cecilia Escobar recurre a las entrevistas que le hizo a la bisnieta de don Manuel Orihuela, doña Eulalia Ezeta, y logra con ello rescatar la vida personal del licenciado. Nos asegura que él era una persona conservadora que estudió la carrera de derecho en la Escuela Nacional de Jurisprudencia, y que fungió como juez y maestro de derecho. Sobre todo, que era muy católico. Tuvo tres matrimonios y una vasta descendencia, por la cual se preocupó escribiendo dos manuales, uno para sus hijos y el otro para sus hijas, que es el que conocemos. Además, su inquietud principal fue dejar consejos claros sobre modales y valores a su familia.

Se interesó el licenciado Orihuela por instruir y educar a sus hijas con una formación estricta, asegurando que su interés era buscar el equilibrio; es decir, no abusar de los bienes materiales ni de los sentimientos, ser una persona honrada y gente de bien sin olvidar que las únicas responsables de los actos en la vida eran ellas mismas. Su interés por educar a sus hijas fue tal que contrató maestros particulares, sobre todo de piano y pintura.

En el capítulo tercero, con un título muy barroco: "Las causas antes del enamoramiento. Las características de un pollo, lo que significaba ser una muchacha decente y las distintas maneras de comunicar el amor", se tratan las relaciones entre hombre y mujer, las cuales siempre han sido objeto de atención, así que don Manuel asegura que si era muy importante la apariencia física, lo era más el alma de la persona. Por ello, por medio de cuentos más que de consejos, nos habla de lo importante que era buscar un marido que estuviera a la altura de la mujer. Incluso, en varias páginas comenta esas relaciones, pero nunca llega a la parte íntima de ellas. El siguiente es el consejo que les daba a las mujeres que buscaban marido:

\footnotetext{
[...] las jovencitas a que llaman pollas [...]

¿Que digo jovencitas! Cotorronas deben también entrar en la colada.

No miran si su genio es bueno o malo:

Si por carácter es enamorado:

Si tiene educación: Si es caprichudo:

Si es muy tonto, si es franco ó es mezquino:

Si tiene religión o es impío (Escobar, 2005: 115).
}

Asimismo, hace mención del galanteo, de las modas, del uso del rebozo y de la mantilla española, y asegura que para que el novio no las abandonara, el pudor era lo más importante, y también no 
tener correspondencia escrita. Incluso, en relación con la formalización de la relación, da consejos sobre los preparativos de la boda, desde el vestido hasta la música, pasando por la hora de servir el banquete y las actitudes de los invitados.

En el capítulo cuarto, "La limpieza: ¿una posición social?”, se analizan los consejos de la limpieza como una actividad importante para catalogar a las personas dentro de un grupo social definido, y, por supuesto, la clase media se consideraba la más limpia. Tener agua para bañarse con frecuencia mostraba lujo, ocio y bienes, debido a que la mayoría de las casas no contaban con drenaje ni con instalaciones que llevaran el agua. El aguador era quien se encargaba de llevar a los hogares el precioso líquido, sirviéndose de un chocol y un jarrito.

El hábito de la limpieza estaba ligado a la economía, y ser una persona limpia implicaba que se era una persona ahorrativa y precavida, ya que así se evitaban los gastos de los doctores, las boticas y los dolores.

En el manual se dan consejos para la limpieza de la boca, de las manos, de los pies, de la cabeza, de la cara y del vestido. A manera de ejemplo, mencionaré el peinado, que fue una parte importante en el arreglo de las mujeres. La moda era usar el cabello recogido en chongo o crepé, llegándose al punto de usar retazos de tela o pelo ajeno para causar el efecto deseado. Sin embargo, Orihuela previene los efectos adversos de esas costumbres: "ciertas piezas, crepé que ustedes llaman, suelen estar llenas de retazos de trapos de colores, y muy sucios, y en algunos han visto piojos, liendres y aun una cucaracha machacada" (Escobar, 2005: 48). En la cara no debía ponerse colorete, porque éste envejecía el rostro, y en cuanto al vestido, aseguraba que una señorita decente debía trabajarlo con sus manos: "es propio de una mujer, muy de su casa, el saber remendar y coser" (Escobar, 2005: 47).

En el quinto y último capítulo, titulado "La función de la limpieza en el hogar”, se habla de cómo debía estar la casa: ordenada y limpia. Se menciona el aseo de la casa y se insiste en la costumbre de limpiar la sala, los corredores, las macetas, el comedor, la mesa, los manteles, las tasas, los posillos, los vidrios, las cortinas, las escupideras, las alfombras, los colchones, las almohadas, las pasaderas y los braseros, así como de quitar cochambre de casos y cuchillos, saber utilizar las escobas correspondientes, y, sobre todo, de las bacinicas, dándose consejo de cómo quitarles los malos olores. 
También se señala cómo se debía atender a las visitas y qué vajilla utilizar para las personas de confianza y algunos invitados que no lo eran, asegurándose que era costumbre muy generalizada guardar algunos trastos muy vistosos para ciertas personas de respeto y presentar lo malo a las que llama personas de confianza y muy de aprecio, cuando debía ser al contrario, dando lugar primero a las amistades.

En este apartado se habla de la servidumbre, de la relación que se debía tener con los criados, e incluso se menciona un reglamento dictado por Santa Anna en 1868 donde se estipulan los salarios de los empleados domésticos. Asimismo, se dan consejos de cómo administrar el tiempo libre la visita a los amigos o familiares, las salidas a los bailes, teatros o fiestas, y algún paseo por La Alameda, La Viga o las calles principales de la ciudad de México. Sobre los bailes, se asegura que su objeto era que los jóvenes conocieran a su pareja. Las otras diversiones populares eran el paseo y el teatro.

En suma, las buenas maneras, los valores morales y el desenvolvimiento personal eran los elementos importantes para ser aceptado en la sociedad, asegurándose que una persona "civilizada" era bienvenida en cualquier grupo.

Si un individuo no tenía una educación completa; es decir, si no había sido educado con valores morales y cívicos, muy difícilmente iba a poder desarrollarse en sociedad. Si una mujer o un hombre cometían una falta moral, rara vez ésta se podía remediar, en virtud de que la sociedad era un fiscal y un juez inflexible que castigaba severamente estas faltas "sociales".

El elegir "estado" era lo más grave que al hombre o la mujer podía acontecer, pues se trataba de un acto de por vida, y encontrar una pareja decente era lo más difícil para la vida.

La amistad es otro valor de suma importancia que se destaca en el manual, y se dice de ella que era una relación honesta y recíproca que podía durar para toda la vida.

El libro viene enriquecido con un glosario de palabras en desuso y una amplia bibliografía, así como con la consulta de los periódicos de la época, como fueron El Siglo XIX, El Globo, El Diario de los Niños, El Álbum de la Mujer, y El Diario.

Es una delicia leer la segunda parte, la versión paleográfica del manual de don Manuel Orihuela, no sólo por la manera como está escrito, en verso, sino también por la riqueza que en él se guarda.

A manera de conclusión, recordemos que los manuales de urbanidad son un objeto de estudio para la reconstrucción de la 
historia social del lenguaje, una historia cuya finalidad es la de comprender y aprender a caracterizar las sociedades por medio del estudio de sus hábitos, derechos y deberes, costumbres, prejuicios y saberes lingüísticos; una historia que coloca el análisis del comportamiento lingüístico en el plano simbólico. El manual de Orihuela es, así, el espejo de las prácticas sociales de la vida urbana mexicana de finales del siglo XIX, huella cuyo estudio resulta vital para una arqueología social y lingüística de esa época, dado el valor sociopragmático que encierra su concepto de la cortesía social y verbal, en particular.

Éste es un libro que la autora nos pone en las manos y con el cual nos hace partícipes de los consejos que su familia, como gente decente, conoce, y que nosotros también debemos conocer.

\section{Obras consultadas}

Ariés, Philippe y Duby Georges (dirs.), (2001), Historia de la vida privada. De la Revolución francesa a la Primera Guerra Mundial, Madrid, Taurus.

Carreño, Manuel Antonio (1853), Manual de urbanidad y buenas maneras, Caracas, Educen.

Gonzalbo-Aizpuru, Pilar y Cecilia Rabell-Romero (coords.) (1992), Familia y vida privada en la historia de Iberoamérica, México, El Colegio de México-unam.

Recibida: 18 de enero de 2006. Reenviada: 27 de enero de 2006. Reenviada: 27 de septiembre de 2006. Liberada: 03 de octubre de 2006

María Teresa Jarquín Ortega. Doctora en Historia de América por la Universidad Complutense de Madrid y doctora en Historia de México por el Colegio de México, A.c. Pertenece al Sistema Nacional de Investigadores (SNI, nivel I). Fue presidenta de El Colegio Mexiquense, entre 1990 y 1998, donde actualmente es profesora-investigadora de tiempo completo. Su campo de estudio y reflexión ha sido la historia novohispana y la historia regional del Estado de México. Desarrolla las siguientes investigaciones: "Las encomiendas en el Valle de Toluca", "Los condes de Santiago Calimaya” y "La Construcción de la Iglesia del pue- 
blo de Metepec". Es coordinadora del diplomado: "Historia Sociopolítica del Estado de México”.

Recibió el Premio Nacional Banamex Atanasio G. Sarabia de Historia Regional Mexicana 1986-1987, por el trabajo: "Metepec. Historia de la formación de un pueblo novohispano". Dicho libro se publicó con el título Formación y desarrollo de un pueblo novohispano: Metepec en el valle de Toluca, El Colegio Mexiquense, A.C.-Ayuntamiento de Metepec. Sus últimos libros son: la Breve Historia Ilustrada del Estado de México, El Colegio Mexiquense, A.C.-Instituto Mexiquense de Cultura/Gobierno del Estado de México; y Brazo de Puma: Acolmiztli Nezahualcoyotl. Historia de un rey de Tezcoco, Instituto Mexiquense de CulturaCONACULTA. 